University of Wollongong

Research Online

Faculty of Social Sciences - Papers (Archive) Faculty of Arts, Social Sciences \& Humanities

2013

Personality trait change and life satisfaction in adults: The roles of age and hedonic balance

Christopher A. Magee

University of Wollongong, cmagee@uow.edu.au

Leonie M. Miller

University of Wollongong, leoniem@uow.edu.au

Patrick C.L Heaven

Australian Catholic University, pheaven@uow.edu.au

Follow this and additional works at: https://ro.uow.edu.au/sspapers

Part of the Education Commons, and the Social and Behavioral Sciences Commons

Research Online is the open access institutional repository for the University of Wollongong. For further information contact the UOW Library: research-pubs@uow.edu.au 


\title{
Personality trait change and life satisfaction in adults: The roles of age and hedonic balance
}

\begin{abstract}
This paper examines whether changes in personality traits influenced life satisfaction (LS). This involved investigating whether these associations were moderated by age and mediated by hedonic balance (i.e., positive and negative affect). Participants included 11,104 Australian adults aged 18-79. years, with data available from two time points (baseline and 4-year follow up). Latent difference score modeling indicated that increased neuroticism was associated with lower LS, whereas increased extraversion, conscientiousness, and agreeableness were associated with higher LS. These relationships were moderated by age, and were less evident in older adults. Hedonic balance partially mediated the relationships between change in neuroticism and extraversion with LS. These findings provide important insights into longitudinal associations between personality change and LS.
\end{abstract}

\section{Keywords}

age, trait, personality, hedonic, change, roles, balance, life, adults, satisfaction

\section{Disciplines \\ Education | Social and Behavioral Sciences}

\section{Publication Details}

Magee, C. A., Miller, L. M. \& Heaven, P. C.L. (2013). Personality trait change and life satisfaction in adults: The roles of age and hedonic balance. Personality and Individual Differences, 55 (6), 694-698. 
Personality Trait Change and Life Satisfaction in adults: The roles of age and hedonic balance.

\begin{abstract}
This paper examines whether changes in personality traits influenced life satisfaction (LS). This involved investigating whether these associations were moderated by age and mediated by hedonic balance (i.e., positive and negative affect). Participants included 11,104 Australian adults aged 18-79 years, with data available from two time points (baseline and 4year follow up). Latent difference score modeling indicated that increased neuroticism was associated with lower LS, whereas increased extraversion, conscientiousness, and agreeableness were associated with higher LS. These relationships were moderated by age, and were less evident in older adults. Hedonic balance partially mediated the relationships between change in neuroticism and extraversion with LS. These findings provide important insights into longitudinal associations between personality change and LS.
\end{abstract}




\section{Introduction}

Subjective well-being (SWB) refers to how individuals evaluate their lives, and encompasses life satisfaction (LS), happiness, job satisfaction, and emotional reactions to events (Diener et al., 2003 and Realo and Dobewall, 2011). It has implications for numerous outcomes including marriage quality, job performance, social functioning, health, and quality of life (Realo \& Dobewall, 2011). LS is an important cognitive component of SWB that incorporates an individual's subjective judgment and/or evaluation of their life drawing on any information they deem relevant (Diener et al., 2003). It predicts happiness and quality of life (Diener et al., 2003), and has been widely examined in a range of different disciplines.

Several studies have reported relationships between personality traits and LS (Boyce et al., 2013, Mroczek and Spiro, 2005 and Specht et al., 2013). For instance, extraversion (E), conscientiousness (C), and agreeableness (A) are positively associated with LS, with neuroticism (N) inversely associated with LS (Mroczek \& Spiro, 2005); openness to experience (O) is not a consistent correlate of LS (Heller, Watson, \& Illies, 2004). Factors such as hedonic balance (i.e., positive and negative affect) have been proposed to underlie the association between personality traits and LS (Schimmack, Radhakrishnan, Oishi, Dzokoto, \& Ahadi, 2002).

The objective of this paper is to investigate whether changes in personality traits over time are associated with LS. We extend on existing literature by examining whether these longitudinal relationships are moderated by age and mediated by hedonic balance. In aggregate, this paper aims to provide an improved understanding of the longitudinal relationship between personality change and LS.

\subsection{Personality change and LS}


Longitudinal studies have examined the relationship between personality and LS, with personality traits assessed at a single time-point (i.e., at baseline). Although there is evidence of stability in personality traits, a potential limitation of these studies is that there is potential for continued personality development across the life span (Roberts and DelVecchio, 2000, Specht et al., 2011 and Turiano et al., 2012). Longitudinal studies have shown that levels of C and A increase with age, whereas N gradually decreases (Roberts \& Mroczek, 2008); O increases in young adulthood, stabilises during middle adulthood, and declines thereafter (Roberts and Mroczek, 2008 and Specht et al., 2011). Certain facets of E such as social dominance may also change with age (Roberts and Mroczek, 2008 and Specht et al., 2011).

Personality change likely reflects a combination of genetic (e.g., intrinsic maturation) and environmental factors, such as changing physical and social environments, and significant life events (McCrae and Costa, 2008, Roberts and Mroczek, 2008 and Specht et al., 2011). It addition, it has been linked with a range of outcomes (Magee et al., 2013, Mroczek and Spiro, 2007, Roberts and Mroczek, 2008 and Turiano et al., 2012). For instance, individuals with increased $\mathrm{N}$ over time have poorer mental and physical health, whereas increased E is linked with improved health (Magee et al., 2013, Mroczek and Spiro, 2007, Roberts and Mroczek, 2008 and Turiano et al., 2012). Boyce et al. (2013) found that personality change predicted LS in a sample of 8625 Australian adults aged 15-93 years old drawn from the Household, Income and Labour Dynamics in Australia (HILDA) Survey. In particular, increases in E, A, C and O over time were associated with higher LS, whereas increases in $\mathrm{N}$ were linked with lower LS.

An important consideration when looking at these associations is that the nature and rate of changes in personality and LS vary by age. For instance, personality change is most pronounced during young adulthood and becomes less marked with increasing age. Thus, the effects of personality change on LS could be greater in younger than older adults. LS is high 
during young adulthood, declines in middle adulthood, and increases during older adulthood (Realo \& Dobewall, 2011). Changes in personality traits may partially underlie the decline in LS observed during young adulthood. However, as personality change becomes less pronounced with increasing age, other factors (e.g., retirement) may influence LS in older age with personality change being less influential. Therefore, it is important to investigate whether age moderates the associations between personality change and LS.

\subsection{Hedonic balance as a mediator}

A range of mechanisms may link personality change with LS. Schimmack, Radhakrishnan, et al. (2002) proposed a mediator model to explain the relationship between baseline measures of personality and LS. This model involved conceptualising the relationship between personality and LS as a system mediated by hedonic balance (the ratio of positive to negative affect experienced by an individual). The mediator model proposes that higher E could facilitate expansion of one's social networks and interactions, leading to a positive hedonic balance where positive affect outweighs negative affect. In turn, the positive hedonic balance could promote more favourable ratings of LS (Mroczek \& Spiro, 2005). In contrast, higher $\mathrm{N}$ is linked with greater emotional reactivity to life events, which could increase the likelihood of experiencing more negative emotions such as depression and anxiety (Mroczek \& Spiro, 2005). High N could therefore promote a negative hedonic balance, and lead to lower ratings of LS.

This model has received some support, with the relationships of baseline measures of $\mathrm{N}$ and $\mathrm{E}$ with LS found to be mediated by hedonic balance (Schimmack et al., 2002 and Schimmack et al., 2002). Hedonic balance could also account for the associations between personality change and LS. This is because individuals who become more neurotic over time may experience a negative hedonic balance which could contribute to poorer LS. In 
contrast, individuals who become more extraverted over time could derive more pleasure out of doing things they enjoy (a positive hedonic balance) and hence have higher LS. These pathways have yet to be examined in relation to personality change.

\subsection{Aims of this study}

The objective of this paper was to investigate the relationship between personality change and LS in adults using data from the HILDA survey. Boyce et al. (2013) previously examined HILDA data and using fixed effects regression found that changes in personality traits were associated with LS. Although these findings provided important insights, fixed effects regression removes between-subject variation from the model to focus on withinsubject variation. One problem with this approach is that it removes factors considered to be stable over time but that may contribute to between-subjects differences. As outlined above, age is one between-subjects factor that could moderate the association between personality change and LS, but this cannot be captured in a fixed-effects model. Therefore in the present article, we utilised latent change score modeling which not only estimates both betweensubject and within-subject differences in change, but minimises measurement error over time by expressing personality change as a latent variable (Selig \& Preacher, 2009). In addition, it allows us to extend on existing research by examining whether age moderates these associations and whether hedonic balance is a mediator linking changes in $\mathrm{N}$ and $\mathrm{E}$ with LS.

\section{Methods}

\subsection{Participants and design}

The HILDA Survey is a longitudinal study that collects data through interviews and self-completion surveys on household and family variables from a broadly representative sample of Australians (Wooden, Freidin, \& Watson, 2002). Data were first collected in 2001 
(Wave 1), with 13,969 participants providing data; follow up data are collected every 12 months (Wooden et al., 2002). Approval to use the HILDA data was obtained from our university's Human Research Ethics Committee. We focused specifically on data from Waves 5 and 9, as these are the two time points where information on both personality and LS are available. We refer to Waves 5 and 9 as Times 1 and 2, respectively in the remainder of this paper.

The sample included 11,104 adults aged $20-79$ years $(M=45.27, \mathrm{SD}=15.59)$ at Time 1, which included a relatively equal proportion of males (47.3\%) and females (52.7\%). Data were available from 9323 participants at Time 2, indicating an attrition rate of $16.0 \%$. Missing data were dealt with using Full Information Maximum Likelihood estimation, which is preferred over other methods (e.g., imputation and pairwise deletion) because of greater efficiency and reduced bias (Bandalos, 2002).

\subsection{Measures}

\subsubsection{Personality}

Personality was assessed at Times 1 and 2 using a 36-item version of Goldberg's Big Five Markers Scale (Saucier, 1994). Each item consists of a single adjective (e.g., "talkative”) requiring participants to indicate how well each item described them on a 7-point Likert scale from “does not describe me at all” to "describes me very well”. N consisted of eight items, with adjectives such as jealous, envious, and selfish (Cronbach's $\alpha=0.83$ ). C comprised seven adjectives reflecting organization and orderliness $(\alpha=0.79)$. E was reflected by seven adjectives representing talkativeness and liveliness $(\alpha=0.75)$, with $\mathrm{A}$ assessed according to four items reflecting warmth and kindness $(\alpha=0.78)$. Finally, $\mathrm{O}$ was reflected by six items encompassing creativity, complexity, and imagination $(\alpha=0.74)$. 


\subsubsection{Life satisfaction}

LS was assessed using a single item: 'All things considered, how satisfied are you with your life as a whole these days?' which was assessed on an 11-point scale from 'dissatisfied' to 'satisfied'. This widely used item has been shown to produce reliable and valid indications of LS ( Diener et al., 2003, Fujita and Diener, 2005, Realo and Dobewall, 2011 and Veenhoven, 1996), with scores corresponding closely with LS scales that include multiple items ( Realo and Dobewall, 2011 and Veenhoven, 1996).

\subsubsection{Positive and negative affect}

Nine items drawn from the Short-Form Health Survey 36 were used to assess positive and negative affect. Four items examined the extent to which an individual had 'been a happy person', 'felt full of life', 'felt calm and peaceful', and had 'a lot of energy' over the past 4 weeks; individuals responded on a six-point Likert scale from 'all of the time' to 'none of the time'. These items were considered to reflect positive affect (Cronbach's $\alpha=.87$ ). The remaining five items assessed whether individuals had felt nervous, 'down in the dumps', down, worn out, and tired over the past 4 weeks on the same six point scale. These items were used to construct a scale of negative affect (Cronbach's $\alpha=.87$ ).

\subsection{Statistical analysis}

There are many approaches to estimating change over time. A simple approach is to calculate a raw change score by subtracting the Time 2 value from the Time 1 value. However, raw change scores are prone to measurement error especially when internal consistencies of these scales are lower. The reliability of the change score also depends on assumptions such as covariance and normality being met. For example, the reliability of the change score decreases as the covariance between the Times 1 and 2 scores increase. This is a 
problem since one would typically expect Times 1 and 2 scores to be correlated over time, particularly in the context of personality traits.

Latent change score modeling overcomes many of these issues (Ferrer and McArdle, 2010 and McArdle, 2009). Rather than summing item scores to estimate constructs at each time point, this approach utilises structural equation modeling to specify Times 1 and 2 scores as latent variables (Ferrer and McArdle, 2010 and McArdle, 2009). A latent change score is then modeled, which results in a measure of change that is error free (because of fixed factor loadings) and not dependent on restrictive assumptions.

In this paper, we examined the longitudinal associations between personality (baseline personality and personality change) and LS using latent change score modeling (Ferrer and McArdle, 2010 and Selig and Preacher, 2009) performed with Mplus version 6.11 (Muthén \& Muthén, 1998-2010). A simplified version of this model is shown in Fig. 1. Each personality subscale was examined as a latent variable, with items parcelled to ensure a parsimonious model (Bandalos, 2002 and Little et al., 2007). This involved randomly assigning relevant items into two parcels, and keeping parcel membership consistent at Times 1 and 2. The change in each personality trait between Times 1 and 2 was modeled as a latent change variable ( Ferrer and McArdle, 2010 and Selig and Preacher, 2009). The model included age and sex as covariates, and controlled for LS assessed at Time 1. 


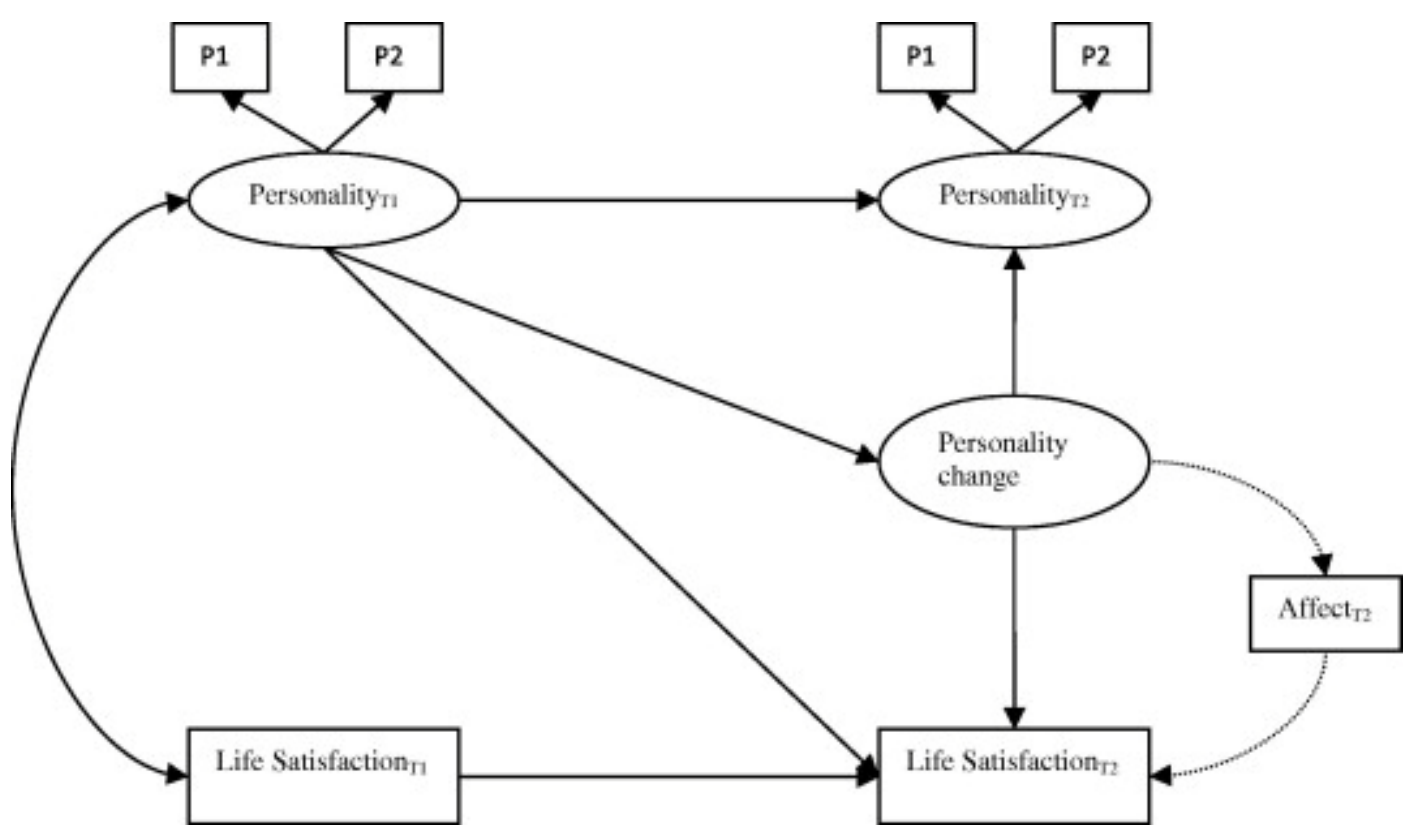

Fig. 1. The relationship between personality change and life satisfaction. This model was extended to also test whether positive and negative affect mediated the relationship between personality change and life satisfaction.

Birth cohort-by-personality change interactions were then added to examine whether the relationship between personality change and LS differed by age. We examined four birth cohort categories at Time 1 (2005): 20-34 years (1971-1985), 35-49 years (1956-1970), 5064 years (1941-1955), and 65-79 years (1926-1940). The age categories used in the present paper provide an indication of young (20-34 years), middle aged (split into two categories: 35-49 and 50-64 years), and older adults (65-79 years). These categories are important given that a number of studies have reported different rates of personality change between young, middle, and older adults. Significant interactions were further investigated by performing the analyses again, stratified according to birth cohort.

The third phase of the analysis involved adding positive and negative affect to the model (with birth cohort-by-personality change interactions removed). This enabled examination of two indirect paths linking personality change with LS through positive affect and negative affect (both assessed at Time 2), controlling for positive affect and negative affect at Time 1. The significance of each indirect path was examined using using 
bootstrapping with 5000 resamples, and assessed according to 99\% confidence intervals (Little et al., 2007 and Selig and Preacher, 2009)

\section{Results}

Baseline measures of personality were associated with LS at Time 2, with $\mathrm{N}$ inversely associated with LS, whereas C, E, O, and A were positively associated with LS (Table 1). Personality change was associated with LS, with increased $\mathrm{N}$ over time linked with lower LS, and increased C, E, and A linked with higher LS. The model fit was appropriate as indicated by comparative fit index (.94), Tucker-Lewis index (.91), root-mean-square error of approximation (.06), and the standardized root-mean-square residual (.04) (Hu \& Bentler, 1998).

Table 1. Relationship between personality (baseline personality and personality change) and life satisfaction according to birth cohort. Results are presented as standardized beta coefficients.

\begin{tabular}{|c|c|c|c|c|c|}
\hline & $\begin{array}{l}1971-1985 \\
(N=3175)\end{array}$ & $\begin{array}{l}1956-1970 \\
(N=3726)\end{array}$ & $\begin{array}{c}1941-1955 \\
(n=2662)\end{array}$ & $\begin{array}{c}1926-1940 \\
(n=1541)\end{array}$ & $\begin{array}{c}\text { Total } \\
(N=11,104)\end{array}$ \\
\hline Baseline N & $-.11^{*}$ & $\mid-.09^{*}$ & $-1.10^{*}$ & $-.10^{*}$ & $-.09^{*}$ \\
\hline Baseline C & $.09^{*}$ & $\mid .03$ & $.06^{*}$ & -.01 & $.05^{*}$ \\
\hline Baseline E & $.08^{*}$ & $.09^{*}$ & $.05^{*}$ & .04 & $.07^{*}$ \\
\hline Baseline $\mathrm{O}$ & -.04 & $-.06^{*}$ & $-.05^{*}$ & -.02 & $-.05^{*}$ \\
\hline Baseline A & $.07^{*}$ & $.09^{*}$ & $.08^{*}$ & .08 & $.08^{*}$ \\
\hline$N$ change & $-.16^{*}$ & $-.14^{*}$ & $-.08^{*}$ & -.06 & $-.12^{*}$ \\
\hline C change & .05 & .04 & .02 & .05 & $.04^{*}$ \\
\hline E change & $.10^{*}$ & $.14^{*}$ & $.11^{*}$ & -.02 & $.10^{*}$ \\
\hline O change & -.03 & .04 & .01 & -.02 & .01 \\
\hline
\end{tabular}




\begin{tabular}{|l|c|c||c||c|c|}
\hline & $\begin{array}{c}1971-1985 \\
(N=3175)\end{array}$ & $\begin{array}{c}1956-1970 \\
(N=3726)\end{array}$ & $\begin{array}{c}1941-1955 \\
(n=2662)\end{array}$ & $\begin{array}{c}1926-1940 \\
(n=1541)\end{array}$ & $\begin{array}{c}\text { Total } \\
(N=11,104)\end{array}$ \\
\hline \hline A change & $.12^{*}$ & $.05^{*}$ & .01 & .05 & $.05^{*}$ \\
\hline
\end{tabular}

$* \mathrm{p}<.05$

In the second phase of the analyses, the relationship between $\mathrm{N}$ change and LS varied significantly by birth cohort $(\beta=.018, p=.006)$. Investigation of these effects indicated the relationship between change in $\mathrm{N}$ and LS was most pronounced in the younger adult group $(\beta=-.16, p<.001)$ and not evident in the oldest group. The association between change in $\mathrm{E}$ and LS varied by birth cohort $(\beta=-.03, p=.018)$, with effects evident in all groups except the oldest group. Finally, the relationship between change in A and LS varied by birth cohort $(\beta=-.03, p=.016)$. Again the effects were evident in all groups except the oldest group. The final phase of the analyses indicated significant relationships between positive affect and higher LS $(\beta=.09, p<.001)$, and between negative affect and lower LS $(\beta=-.05, p<.001)$. Increased $\mathrm{N}$ was significantly associated with lower positive affect $(\beta=-.21, p<.001)$ and higher negative affect $(\beta=.26, p<.001)$. The indirect paths linking change in $\mathrm{N}$ with LS through positive affect $(\beta=-.01995 \%$ Confidence Interval $[-.023,-.015])$ and negative affect were significant $(\beta=-.013[-.017,-.010])$. This suggested the relationship between increased $\mathrm{N}$ and lower LS was mediated by higher negative affect and lower positive affect. Furthermore, increased E was associated with higher positive affect $(\beta=.42, p<.001)$ and lower negative affect $(\beta=-.39, p<.001)$. The association between increased $\mathrm{E}$ and higher LS was partially mediated by higher positive affect $(\beta=.037[.028, .048])$ and lower negative affect $(\beta=.020[.013, .029])$.

\section{Discussion}


Increases in $\mathrm{N}$ over time were associated with lower LS, whereas increases in $\mathrm{E}, \mathrm{C}$, and $\mathrm{A}$ were associated with higher LS. These findings are consistent with Boyce et al. (2013) who also examined the HILDA survey but used a different statistical approach. In addition, our results indicate the effects of personality change on LS varied significantly by birth cohort with effects more pronounced in the younger adult groups. For example, the relationship between change in $\mathrm{N}$ and LS was strongest in the younger cohorts, but diminished with age. The apparent influence of change in $\mathrm{N}$ on LS for the younger cohorts might reflect vulnerability to the pressures and uncertainties of young and middle adulthood (e.g. development of a career and financial autonomy, establishment of key relationships) and broader social issues (e.g. climate change, economic uncertainty) that may have greater relevance for these adults (Roberts and Mroczek, 2008 and Specht et al., 2011).

Changes in N, E and A were not associated with LS in the eldest cohort, which could reflect the smaller magnitude of personality change observed with increased age (Roberts \& Mroczek, 2008). Declining physical and cognitive functioning, and chronic health conditions may have larger effects on LS relative to personality in this older cohort. In combination, these factors could explain why the nature of the relationships of changes in N, E, and A with LS are significantly more pronounced in younger adults.

A key contribution of the present paper is that hedonic balance partially mediated the association between changes in $\mathrm{N}$ and $\mathrm{E}$ with LS. In particular, increased $\mathrm{N}$ was associated with reduced LS through lower positive affect and higher negative affect; increased E was associated with higher LS through higher positive affect and lower negative affect. These findings are consistent with Schimmack, Radhakrishnan, et al.’s (2002) mediator model, which has not been previously applied to personality change. Increases in $\mathrm{N}$ over time could reflect changes in work and family life that contribute to greater emotional reactivity to life events (Specht et al., 2011). More generally, during the period of this study (2005-2009), the 
global financial crisis occurred, with resultant financial strain likely to have contributed to considerable stress and hardship for many individuals (Sargent-Cox, Butterworth, \& Anstey, 2011). According to the mediator model, the effects of increased N on LS arise because of a negative hedonic balance, which occurs when negative emotions outweigh the experience of positive emotions (Schimmack, Radhakrishnan, et al., 2002). Over time, this negative hedonic balance could contribute to poorer LS.

Increased E could reflect greater social support derived through expansion of social networks as adults enter the workforce, have families, experience more success, and become more assertive and confident (Roberts \& Mroczek, 2008). These factors could lead to a positive hedonic balance through heightened emotional support and experience of positive emotions over time; this could translate into higher LS (Schimmack, Radhakrishnan, et al., 2002). Greater E may also increase an individual's likelihood of fulfilling key aspects of a life script, which in turn may lead to greater positivity in the cognitive assessment of LS. Hedonic balance appears to partially mediate the relationship between changes in $\mathrm{N}$ and $\mathrm{E}$, and LS. However, partial mediation implies that other factors (e.g., changes in health status and significant life events such as marriage and having children) may also underlie these relationships. These and other factors may explain the links between increases in C and A, and improved LS observed in this study. For example, individuals with increased C may experience more success at work, have better work-life balance, and remain healthier due to engaging in health enhancing behaviours such as regular physical activity (Bogg \& Roberts, 2004). This may also lead to more positive life experiences and higher LS. Individuals who became more agreeable over time were also more likely to have higher LS. This is potentially because these individuals are more likely to develop higher quality friendships, have more career success, deal with stressful situations in a more positive manner, and have less conflict 
in social relationships (Jensen-Campbell, Knack, \& Gomez, 2010). This could also lead to more positive life experiences and hence greater LS.

\subsection{Strengths and limitations}

The large sample size was broadly representative of Australian adults and allowed us to investigate the relationships in different birth cohorts. The analytic approach is a rigorous way of assessing these relationships, and provides important insights into the nature of the associations between personality change and LS. Further, the use of an a priori model (Hedonic balance; Schimmack, Radhakrishnan, et al., 2002) to examine and further refine the relationship between personality change and LS indicates that temperament could make a genuine contribution to how well satisfied an individual is about their life course.

This study relied on a single item of LS, which is commonly used to assess LS (Diener et al., 2003, Fujita and Diener, 2005, Realo and Dobewall, 2011 and Veenhoven, 1996). Although this has been shown to produce valid data, the single-item measure may not tap into specific components of LS, or lack sensitivity to changes in LS over time. Similarly, the Minimarkers scale (Saucier, 1994) of personality is widely used but consists of only 36-items which does not allow insight into more specific personality subtypes (e.g., perfectionism) which could be important for LS. The measure of $\mathrm{N}$ assesses components of neuroticism such as anxiety, but the valence of all items is negative, which may have contributed to the skewed distribution of scores in the sample. Finally, the O domain primarily reflected Intellect and overlooked other components of O which may also affect LS.

The present research covered a relatively brief snapshot of the total life trajectory, and larger periods of observation may be required to observe the full effects of personality change. This snapshot encompassed two time points for personality, which when examined using latent difference score modeling, provided a useful insight into the temporal relationship between these variables. However, the use of two time points to assess longitudinal relationships is 
limited and three or more time-points would allow for a more detailed investigation of these associations. Finally, although the large sample size is a key strength of this paper, the considerable statistical power means that small effect sizes are significant. The complex covariance structures within the model make it difficult to determine the effect size for each path. We therefore recommend that these results are interpreted cautiously. This is also important because personality change is likely to be incremental, and the effects of these changes could thus take a considerable amount of time to be realised and influence outcomes such as LS. Future studies that can obtain multiple repeated measures over a larger time frame would assist in clarifying this possibility.

\section{Conclusion}

LS is an important psychological construct, providing insights into an individual's well-being and assessment of their life, and has been shown to vary with changes in personality over time (Boyce et al., 2013). The current work suggests this finding can be considered in relation to hedonic balance, with personality potentially influencing an individual's affect and in turn their levels of LS. We have also highlighted how relationships between change in personality and changes in LS may be different across the age span. These findings are consistent with previous research establishing independent life-course trajectories for both personality and LS. Future research in this area should continue to investigate personality as a dynamic construct, and explore the impact of these changes on measures of health and well-being. Similar to the present paper, this should involve understanding the role of potential mediators such as hedonic balance. 


\section{References}

Bandalos, D. L. (2002). The effects of item parcelling on goodness-of-fit and parameter estimate bias in structural equation modeling. Structual Equation Modeling, 9, 78-102.

Bogg, T., \& Roberts, B. W. (2004). Conscientiousness and health-related behaviors: A metaanalysis of the leading behavioural contributors to mortality. Psychological Bulletin, 130, 887 - 919.

Boyce, C.J., Wood, A.M., Powdthavee, N. (in press). Is personality fixed? Personality changes as much as "variable” economic indicators and mort strongly predicts changes to Life Satisfaction. Social Indicators Research.

Diener, E., Oishi, S., \& Lucas, R. E. (2003). Personality, culture, and subjective well-being: Emotional and cognitive evaluations of life. Annual Review of Psychology, 54, 403 425.

Ferrer, E., \& McArdle, J. J. (2010). Longitudinal modeling of developmental changes in psychological research. Current Directions in Psychological Science, 19, 149-154.

Fujita, F., \& Diener, E. (2005). Life Satisfaction Set Point: Stability and Change. Journal of Personality and Social Psychology, 88, 158 - 164.

Heller, D., Watson, D., \& Illies, R. (2004). The role of person versus situation in Life Satisfaction: A critical examination. Psychological Bulletin, 130, 574-600.

Hu, L.-t., \& Bentler, P. M. (1998). Fit Indices in Covariance Structure Modeling: Sensitivity to Underparameterized Model Misspecification. Psychological Methods, 3, 424-453.

Jensen-Campbell, L.A., Knack, J.M., \& Gomez, H.L. (2010). The psychology of nice people. Social and Personality Psychology Compass, 4, 1042 - 1056. 
Little, T. D., Preacher, K. J., Selig, J. P., \& Card, N. A. (2007). New Developments in latent variable panel analyses of longitudinal data. International Journal of Behavioral Development, 31, 357 - 365.

Magee, C. A., Heaven, P. C. L., \& Miller, L. (in press). Personality change predicts selfreported mental and physical health. Journal of Personality.

McArdle, J.J. (2009). Latent variable modelling of differences and changes with longitudinal data. Annual Review of Psychology, 60, 577 - 605.

McCrae, R. R., \& Costa, P. T. (2008). The Five-Factor Theory of Personality. In O.P. Johns, R. W. Robins \& L. A. Pervin (Eds.), Handbook of Personality: Theory and Research (3rd ed., pp. 159 - 181). New York: The Guilford Press.

Mroczek, D. K., \& Spiro, A. (2005). Change in Life Satisfaction During Adulthood: Findings From the Veterans Affairs Normative Aging Study. Journal of Personality and Social Psychology, 88, 189 - 202.

Mroczek, D. K., \& Spiro, A. (2007). Personality change influences mortality in older men. Psychological Science, 18, 371 - 376.

Muthén, L. K., \& Muthén, B. O. (1998 - 2010). Mplus Users Guide. Sixth Edition. Los Angeles: CA: Muthén \& Muthén.

Realo, A., \& Dobewall, H. (2011). Does life satisfaction change with age? A comparison of Estonia, Finland, Latvia, and Sweden. Journal of Research in Personality, 45, 297 308. 
Roberts, B. W., \& DelVecchio, W. F. (2000). The rank-order consistency of personality traits from childhood to old age: A quantitative review of longitudinal studies. Psychological Bulletin, 126, 3-25.

Roberts, B. W., \& Mroczek, D. (2008). Personality trait change in adulthood. Current Directions in Psychological Science, 17, 31 - 35.

Sargent-Cox, K., Butterworth, P., \& Anstey, K. J. (2011). The global financial crisis and psychological health in a sample of Australian older adults: A longitudinal study. Social Science and Medicine, 73, 1105-1112.

Saucier, G. (1994). Mini-Markers: A brief version of Goldberg's unipolar Big-Five markers. Journal of Personality Assessment, 63(3), 506 - 516.

Schimmack, U., Diener, E., \& Oishi, S. (2002). Life-Satisfaction is a momentary judgment and a stable personality characteristic: The use of chronically accessible and stable sources. Journal of Personality, 70, 345 - 384.

Schimmack, U., Radhakrishnan, P., Oishi, S., Dzokoto, V., \& Ahadi, S. (2002). Culture, Personality, and Subjective Well-Being: Integrating Process Models of Life Satisfaction. Journal of Personality and Social Psychology, 82(4), 582 - 593.

Selig, J. P., \& Preacher, K. J. (2009). Mediation models for longitudinal data in developmental research. Research in Human Development, 6, 144 - 164.

Specht, J., Elgoff, B., \& Schmukle, S. C. (2013). Examining mechanisms of personality maturation: The impact of Life Satisfaction on the development of the Big Five personality traits. Social Psychology and Personality Science, 4, 181 - 189. 
Specht, J., Elgoff, B., \& Schmukle, S. C. (2011). Stability and change of personality across the life course: The impact of age and major life events on mean-level and rank-order stability of the Big Five. Journal of Personality and Social Psychology, 101, 862 - 882.

Turiano, N. A., Pitzer, L., Armour, C., Karlamangla, A., Ryff, C. D., \& Mroczek, D. K. (2012). Personality trait level and change as predictors of health outcomes: Findings from a national study of Americans (MIDUS). Journal of Gerontology Series B: Psychological Science, 67, 4 - 12.

Veenhoven, R. (1996). Happy life-expectancy. Social Indicators Research, 39, 1-58.

Wooden, M., Freidin, S., \& Watson, N. (2002). The Household, Income and Labour Dynamics in Australia (HILDA) Survey: Wave 1. Australian Economic Review, 35, 339-348. 